\title{
TENSIONAMENTO DE VOZES NA PRIMEIRA PÁGINA DO JORNAL: O EPISÓDIO ARACRUZ NA CAPA DE ZERO HORA*
}

Élida LIMA e Maria da Glória DI FANTI Recebido 13, jan. 2010/ Aprovado 29, abr. 2010

\section{Resumo:}

Este artigo tem o objetivo de analisar discursivamente a capa do jornal Zero Hora (RS) do dia 12 de março de 2006, verificando relações dialógicas estabelecidas de modo a recuperar características e efeitos de sentido da cobertura de um evento de grande repercussão na mídia gaúcha, que denominamos para fins de pesquisa como Episódio Aracruz. A análise parte dos pressupostos teóricos desenvolvidos pelo Círculo de Bakhtin e estabelece interlocução com a abordagem ergológica. Por razões metodológicas, a análise está organizada em dois grupos interdependentes. O primeiro apresenta uma reflexão acerca da capa do jornal em estudo e de efeitos produzidos pelos recursos visuais utilizados (como cor, espaço e elementos gráficos). O segundo grupo analisa os recursos verbais eleitos para a construção da capa, considerando (a) designações utilizadas para a chamada sobre o Episódio Aracruze, de modo sucinto, (b) elementos verbais utilizados em outras chamadas, que, por constituírem o mesmo projeto gráfico, mantêm uma interlocução e, assim, produzem efeitos diversos. Os resultados da reflexão indicam que os enunciados analisados, não seguindo as prescrições dos manuais de redação jornalística, são altamente avaliativos na intrínseca relação entre os planos verbal e visual, o que revela a relativa estabilidade dos gêneros e ratifica o estatuto lacunar das normas do trabalho. Nesse processo discursivo, a posição do jornal emerge em um emaranhado de vozes na cobertura do Episódio Aracruz, deixando ressoar, dentre outras relações dialógicas, a ruptura com os movimentos sociais, o que exige uma leitura crítica para compreender os sentidos em circulação.

Palavras-chave: Relações dialógicas. Capa de jornal impresso. Episódio Aracruz.
Este artigo - ampliado e aprofundado - é um desdobramento de uma versão inicial do trabalho Da constituição dialógica da capa de jornal: efeitos de sentido em perspectiva, apresentado no XIII Colóquio Internacional de Comunicação para o Desenvolvimento Regional (LIMA; DI FANTI, 2008). 


\section{Considerações iniciais}

Ao observarmos os gêneros produzidos na esfera jornalística, é possível percebermos que as notícias são uma construção discursiva de um fato, tendo em vista constituírem uma elaboração em que entram em jogo diferentes perspectivas, como a do jornalista, do jornal, do público-alvo, dos patrocinadores, das alianças políticas, dentre outros elementos, o que configura uma performance encenada pelos veículos de comunicação. É válido lembrar, sob esse enfoque, que a notícia é uma das modalidades de apresentação das informações no jornalismo, a qual concentra aspectos da realidade, ou melhor dizendo, desenvolve uma versão da realidade. Mas não é uma versão qualquer, pois é produzida por profissionais especializados, os jornalistas.

Há de se considerar, nesse contexto, que somente são publicadas aquelas notícias que atendem a certos requisitos mercadológicos, ou seja, é necessário que os fatos eleitos, para serem publicizados, tenham o apelo e o valor exigidos pela esfera jornalística. Assim, a seleção, escolha de um assunto e não de outro, é realizada em consonância com as prerrogativas dessa esfera, como, por exemplo, a publicação de informações de interesse público (que possam atingir um grande número de pessoas). Destaca-se, além disso, que as notícias ganham maior ou menor visibilidade dentro desse espaço de produção de discurso a partir da avaliação dos profissionais da comunicação, no que tange aos saberes, história, interesses e perspectivas ideológicas, que se revelam (em maior ou menor intensidade) em suas produções discursivas.

Nesse contexto, chama-nos a atenção a primeira página dos jornais impressos, espaço que reúne uma síntese daquelas notícias consideradas de maior impacto pelos jornalistas. Os fatos que ali figuram, via de regra, ocupam espaços privilegiados nas páginas internas do jornal. Assim, a apresentação "objetiva", que se instala no dizer da capa do jornal impresso, é importante elemento na cena discursiva construída pelos veículos de comunicação para a apresentação das notícias e, portanto, merecedor de uma análise mais detalhada, uma vez que, na sociedade contemporânea, é através das informações que circulam por este espaço que muitos leitores tomam conhecimento de fatos

1 Uma pesquisa maior sobre a cobertura jornalística do Episódio Aracruz está sendo desenvolvida em forma de Dissertação de Mestrado pela acadêmica Élida Lima, com a orientação da Profa. Maria da Glória di Fanti, no Programa de Pós-Graduação em Letras da Universidade Católica de Pelotas (UCPel). da atualidade. Nessa perspectiva, temos como objetivo analisar discursivamente a capa do jornal Zero Hora (Porto Alegre-RS) do dia 12 de março de 2006, verificando relações dialógicas estabelecidas de modo a recuperar características e efeitos de sentido da cobertura de um evento de grande repercussão na mídia gaúcha, que denominamos para fins de pesquisa como Episódio Aracruz. ${ }^{1}$

O fato noticiado ocorreu na madrugada do dia 8 de março de 2006, quando um comboio de 40 ônibus transportou cerca de 
1,5 mil pessoas de Porto Alegre-RS para o município de Barra do Ribeiro-RS, distante 60 quilômetros da capital gaúcha. No local, o grupo entrou no horto florestal da Aracruz e inutilizou aproximadamente três milhões de mudas de eucaliptos, além de estufas e experimentos. Os manifestantes, que protestavam contra a instalação de florestas de eucalipto no Rio Grande do Sul e, futuramente, de uma indústria de celulose, eram, em sua grande maioria, mulheres integrantes do Movimento das Mulheres Camponesas (MMC), vinculado à Via Campesina. $\mathrm{O}$ fato teve grande repercussão nos campos político e jurídico, além de ocupar espaço privilegiado na mídia.

A análise tem como base os pressupostos da teoria dialógica do discurso (BAKHTIN, 1929/1997, 1934-1935/1998, 19521953/2003; BAKHTIN/VOLOCHINOV, 1929/2004), especialmente noções como dialogismo, enunciado, gêneros do discurso, voz e palavra, que auxiliam na compreensão das construções discursivas historicamente situadas no tempo e espaço. Também estabelecemos uma interlocução com as noções desenvolvidas pela ergologia (SCHWARTZ, 1994, 2003), abordagem que considera o "fazer" do trabalhador como uma atividade viva, sempre inovadora, materializado no debate constante entre normas antecedentes e renormalizações. $\mathrm{O}$ aporte dessas teorias possibilita definir a proposta deste estudo no que se refere à observação das notícias destacadas na capa do jornal pela ótica de uma análise dialógica do discurso, sem perder de vista os elaborados processos produtivos e a complexa atividade do jornalista.

Este trabalho é constituído por três seções, seguidas das considerações finais. Na primeira, são apresentadas, de forma sucinta, as noções consideradas relevantes para o embasamento teórico da reflexão. A segunda parte contempla uma breve contextualização da esfera midiática, mais precisamente a jornalística, algumas informações sobre o jornal Zero Hora e sobre o episódio ocorrido no horto florestal da empresa Aracruz Celulose, em Barra do Ribeiro-RS, que mereceu ampla cobertura jornalística em Zero Hora. A terceira seção traz considerações analíticas sobre o objeto em análise neste trabalho, qual seja a capa do jornal Zero Hora do dia 12 de março de 2006, que se configura como uma das edições que mais espaço dedicou à cobertura do Episódio Aracruz.

\section{Teoria dialógica do discurso e abordagem ergológica}

Para fundamentar teoricamente a presente reflexão, partimos dos pressupostos da teoria dialógica do discurso, desenvolvida por Mikhail Bakhtin e seu Círculo (BAKHTIN, 1929/1997, 1934-1935/1998, 1952-1953/2003, 1959-1961/2003; BAKHTIN/ VOLOCHINOV, 1929/2004), e estabelecemos interlocução com a abordagem ergológica (SCHWARTZ, 1994, 2003; SCHWARTZ 
e DURRIVE, 2007), que tem na atividade humana o seu objeto de reflexão.

Sem desconsiderar as relações lógicas, próprias da linguística do sistema, mas ultrapassando-as, Bakhtin (1929/1997, 1952-1953/2003) propõe o estudo da linguagem a partir da sua propriedade dialógica. Considerando a memória discursiva dos enunciados, a heterogeneidade dos discursos e a antecipação dos dizeres (cada enunciado supõe uma resposta), o dialogismo implica o estabelecimento permanente de relações responsivas (relações dialógicas) com discursos de outrem em diferentes direções, o que garante a dinamicidade de sentidos.

Desse modo, para a teoria bakhtiniana, a língua é considerada em situações concretas na materialização de enunciados dialógicos, os quais, funcionando como a unidade mínima de comunicação e um elo na cadeia discursiva, estão sempre em inter-relação com outros enunciados e fazem circular posições avaliativas de sujeitos do discurso. $\mathrm{O}$ enunciado, constituído por dimensões verbais e não-verbais, implica também, como observa Bakhtin (1959-1961/2003), uma relação entre o dado e o criado, no sentido de ressaltar sua dimensão de singularidade, de ressignificação, de irrepetibilidade. Mesmo havendo algo que é dado, mesmo que uma repetição linguística, sempre há criação, renovação, reelaboração, pois as condições de produção do discurso são sempre outras.

Tais observações são importantes para o entendimento dos gêneros do discurso, formas discursivas com estabilidade relativa que possibilitam as interações verbais. Segundo Bakhtin (1952-1953/2003), falamos por meio de gêneros, o que indica, por um lado, a socialização de práticas discursivas e, por outro, a existência de elementos próprios dos gêneros. O tema, o dizível dinâmico de um dado gênero, configurado pelos sentidos em circulação, a forma composicional, a estrutura em diferentes dimensões, e o estilo verbal, recursos linguísticos, se engendram nas produções enunciativas e oferecem pistas intrínsecas à relação empreendida com a esfera de produção, circulação e recepção do discurso. Nas diferentes manifestações de linguagem, emerge também o estilo - dialógico - do sujeito do discurso nas relações empreendidas com outrem (discursos e sujeitos).

Na constituição do enunciado, e também do gênero, há um entrecruzamento de vozes sociais em concorrência, em que se encontram e se distanciam diferentes pontos de vista, visões de mundo. $\mathrm{O}$ enunciado, desse modo, se materializa heterogeneamente e, ao mesmo tempo em que responde a discursos diversos (nem sempre observáveis), apresenta posições ideológicas de quem se responsabiliza pelo dizer (BAKHTIN, 1934-1935/1998). Nesse processo, é fundamental observar, na dimensão verbal, as palavras que constituem os enunciados e, em decorrência os gêneros, pois a escolha de uma palavra e não outra e a sua or- 
ganização no discurso revelam posições assumidas pelo sujeito tanto em relação ao objeto do discurso como em relação ao outro com quem dialoga (seja o interlocutor, seja outro discurso ou sujeito). A palavra, como salienta Bakhtin/Volochinov (1929/2004), funciona como uma zona fronteiriça entre os interlocutores e é um fenômeno ideológico por natureza, o que a configura como enunciado. Na leitura da teoria bakhtiniana, Di Fanti (2009, p.182) observa que "a palavra se materializa como expressão de certa posição valorativa do sujeito, cuja experiência discursiva se desenvolve em uma interação constante e contínua com os enunciados dos outros". Dessa forma, todo discurso é carregado de palavras alheias, que são re-acentuadas, singularizadas em um outro dizer, em novas condições enunciativas.

Ampliando a perspectiva teórica, estabelecemos diálogo com a ergologia, abordagem que, comprometida com a valorização do humano nas trocas laborais, contribui para a compreensão de características do trabalho no que tange às dimensões éticas e históricas dos saberes presentes nas atividades humanas (SCHWARTZ, 1994, 2003; SCHWARTZ e DURRIVE, 2007). Trata-se de um enfoque que, inspirado na ergonomia da atividade, dentre outros movimentos, questiona o paradigma taylorista, ${ }^{2}$ o qual considerava o trabalho a partir da perspectiva dos gestores, sem deixar espaço para a contribuição intelectual do trabalhador. Da ergonomia da atividade, a principal contribuição é o reconhecimento da distância entre o trabalho prescrito e o trabalho real, mostrando que o trabalhador não é um mero executor de tarefas, mas sim um ser humano que, em sua prática profissional, sempre faz algo diferente, singular.

Ampliando os estudos da ergonomia situada e considerando a complexidade da atividade humana, a Ergologia propõe que a análise do trabalho seja feita a partir de uma perspectiva pluridisciplinar (filosofia, ergonomia da atividade, lingüística etc.). Tal postura deve-se ao fato de se considerar as diferentes dimensões que interferem no fazer do trabalhador, como saberes, experiências, projetos, preocupações e anseios.

Para a abordagem ergológica, o ser humano, na atividade de trabalho, é "fabricante" de história, com capacidade de (re) questionar e (re)combinar os saberes, (re)elaborando em permanência novas tarefas para o conhecimento. Schwartz, desse modo, não descarta as prescrições do trabalho, mas sobretudo as redefine no amplo campo das normas antecedentes, as quais, embora mantenham a mesma natureza das prescrições, não se limitam a elas. Para o filósofo, as normas antecedentes são importantes e orientam, em parte, o que vai ser produzido no

2 O termo faz referência a Frederick Taylor e ao método por ele criado de racionalização do trabalho. "vivo da atividade"; entretanto, não pré-definem o real da atividade, já que a história da atividade é sempre inacabada e lacunar (SCHWARTZ, 1994, 2003). 
Considerando a atividade de trabalho como uma atividade industriosa, gerida por um indivíduo complexo, Schwartz (2003) destaca a importância da observação do debate entre normas antecedentes e renormalizações como um meio de criar conhecimento sobre o trabalho. É justamente nesse debate que se pode perceber a atividade de trabalho como lugar de se fazer história, na medida em que o ser humano, tratando daquilo que não é antecipável, subverte as normas, preenche lacunas, chegando a transformar as configurações culturais e sociais, o que nos remete à esfera jornalística.

\section{A esfera jornalística, o jornal Zero Hora e o Episódio Aracruz}

Na sociedade (pós)moderna, a mídia passou a ser o espaço por excelência em que as informações têm curso, trafegam, tomam forma, sendo que os veículos de comunicação encenam uma performance discursiva ao apresentarem as informações do cotidiano como enunciados de determinados gêneros midiáticos. Nessa perspectiva, faz-se necessário problematizar a mídia e suas cenas enunciativas de apresentação de versões da realidade, pois é através das informações que circulam por este espaço que a sociedade contemporânea toma conhecimento dos fatos da atualidade. Dependendo do modo como os enunciados são apresentados, podem, em maior ou menor grau, influenciar a interpretação dos fatos e o comportamento tanto individual quanto coletivo.

O gênero jornalístico difere-se dos outros gêneros midiáticos essencialmente por trabalhar com fatos, acontecimentos da sociedade. Uma de suas modalidades, a notícia, é construída a partir de acontecimentos. Em outras palavras, as notícias que não se baseiam em fatos que tenham ocorrido não são notícias. Trata-se ou de fraude, uma falsificação, ou de um texto pertencente aos gêneros midiáticos voltados ao entretenimento. Ou seja, os aspectos da realidade têm relação direta com as notícias. Por ser um referente que não pode fugir do horizonte dos jornalistas, o real, ou melhor, uma versão dos acontecimentos dados como reais, é atributo das notícias apresentadas nos jornais.

É assim que, na esfera jornalística, a notícia é o gênero que ocupa maior espaço na mídia impressa e pode ser compreendida, em sua estrutura, como o relato de uma série de fatos a partir do fato mais importante (LAGE, 1998). Os enunciados produzidos nesse gênero, oriundos de diferentes esferas da atividade humana, atendem a linhas mestras que regem as operações jornalísticas, descritas nos manuais de redação e estilo (style-

3 Sobre características discursivas do gênero notícia, consultar Grillo (2004), Sant'Anna (2004), Brait e Rojo (2003). books). Os recursos prescritos nesses manuais (precisão dos fatos, texto conciso, discurso citado, exclusão de adjetivos) reclamam efeitos de objetividade, os quais se fazem necessários no gênero jornalístico. ${ }^{3}$ 
A primeira página do jornal (a capa) destaca-se nesse cenário por anunciar notícias consideradas destaque da edição, que chega ao leitor, dentre outras formas, pela distribuição nos endereços dos assinantes ou nos pontos de comercialização (bancas). Ressalta-se assim que a capa tem um papel importante, pois, além de visar despertar o interesse do leitor pelo conteúdo do jornal, consequentemente, pretende vender o jornal. Ou seja, tem relevância para a saúde financeira do negócio jornal, tanto que há uma preocupação extra com a estética e o designer aplicados a essa página. Por contemplar produções enunciativas (verbais e visuais) que trazem à tona embates ideológicos verificados em diferentes segmentos sociais, a capa de jornal configura-se como vasto e rico material para os estudiosos da linguagem que têm como objeto de investigação o discurso dialógico.

Quanto ao jornal Zero Hora, que veicula a capa a ser analisada, é válido destacar que, historicamente, tem deixado ressoar pistas de uma posição contrária aos movimentos sociais de esquerda, seja através das próprias notícias seja por meio de textos publicados nos espaços em que é expressa a opinião da empresa, como nos editoriais. Essa postura assumida por Zero Hora pode ser observada nos outros veículos de comunicação igualmente pertencentes ao Grupo RBS, considerada a maior empresa de comunicação multimídia do Rio Grande do Sul. Além de oito jornais diários, integram o conglomerado uma televisão aberta, afiliada da Rede Globo, uma televisão comunitária, rádios e portais da Internet. Conforme uma pesquisa do Instituto Verificador de Circulação (IVC), publicada em janeiro de 2009, Zero Hora é líder no segmento jornal no estado gaúcho e sétimo colocado no ranking nacional, com uma média diária de 179.934 de circulação em 2008.

A fim de contemplar a proposta deste artigo, faz-se necessário contextualizar o episódio que originou a capa dominical do jornal Zero Hora, do dia 12 de março de 2006, que traz com destaque o enunciado "Impunidade radical". Essa chamada refere-se às notícias publicadas das páginas 4 a 7, 35 e 39 deste dia, as quais integram uma série de reportagens produzida pela equipe de Zero Hora e publicada com destaque no referido jornal durante aproximadamente dez dias, entre 9 e 19 de março, período subsequente à ação de integrantes da Via Campesina, realizada dia 8 de março na Fazenda Barba Negra, em Barra do Ribeiro-RS.

Cerca de 1,5 mil manifestantes se deslocaram de Porto Alegre, onde participavam da $2^{\text {a }}$ Conferência Internacional sobre Reforma Agrária e Desenvolvimento Rural, na PUC-RS, para protagonizar um ato de protesto no horto florestal da multinacional de celulose, em Barra do Ribeiro. Além de lideranças do Movimento Sem-Terra (MST), os manifestantes eram, em sua maioria, integrantes do Movimento das Mulheres Camponesas 
(MMC), ambos vinculados à Via Campesina. A participação de grande número de mulheres também tinha como objetivo chamar a atenção para a data da ação (Dia Internacional da Mulher). $\mathrm{O}$ ato resultou na inutilização de estufas, experimentos e três milhões de mudas de eucalipto, as quais seriam usadas para a formação de florestas, matéria-prima das indústrias de celulose.

Tendo em vista as considerações desenvolvidas sobre a esfera jornalística, o jornal Zero Hora e o Episódio Aracruz, percebe-se a pertinência de se analisar a primeira página do jornal. As estratégias discursivas apresentadas na primeira página têm nas teorias da linguagem uma forte fonte epistêmica, aliada, naturalmente, neste caso, às teorias da comunicação. Além disso, os estudos acerca do trabalho têm se mostrado produtivos para o desenvolvimento de reflexões acerca da atividade jornalística. Logo, é possível contemplar, de algum modo, diferentes áreas do conhecimento de forma a contribuir para a reflexão sobre a construção de efeitos de sentido produzidos na capa de jornal a partir das notícias publicadas sobre temas sociais.

\section{O Episódio Aracruz na primeira página de Zero Hora: algumas considerações}

A esfera jornalística é um espaço privilegiado de instituição e produção de sentidos, a partir de uma encenação discursiva construída pelas informações que ali são publicadas. Para tanto, os profissionais da área lançam mão de estratégias discursivas (eleição de um gênero, seleção lexical, elementos visuais, espaço físico ocupado, seleção de entrevistados, distribuição na página etc.) que manifestam suas escolhas, preferências e posicionamentos diante de fatos do cotidiano. São essas estratégias, ou melhor dizendo, os efeitos de sentido produzidos por elas que serão considerados na análise da capa do jornal Zero Hora do dia 12 de março de 2006, edição que traz ampla cobertura do Episódio Aracruz.

Tais efeitos assumem nova e maior dimensão quando se trata dos enunciados da capa do jornal, muitas vezes única página lida pelos leitores, seja por falta de tempo ou cultura para uma leitura mais detalhada, seja pelo custo do exemplar de jornal impresso. Assim, as construções discursivas desse espaço e os múltiplos entendimentos que delas podem emergir merecem atenção especial dos analistas do discurso.

Para a análise, tem-se como um dos pontos referenciais os

4 Para tanto são considerados o Manual de Redação da Folha de São Paulo (SILVA, 2005) e o Guia de Ética e Responsabilidade Social da RBS/Rede Brasil Sul (2004). manuais de redação e estilo mais comumente utilizados pelos jornalistas, nos quais estão descritas as normas éticas que regem a atividade dos profissionais da área e indicam os critérios de padronização da produção jornalística. ${ }^{4}$ As categorias analíticas estão estruturadas, por razões metodológicas, em dois grupos interdependentes. O primeiro deles apresenta uma reflexão 
acerca da capa do jornal em estudo e de efeitos produzidos pelos recursos visuais utilizados (como cor, espaço e elementos gráficos). O segundo grupo analisa os recursos verbais eleitos para a construção da capa, considerando (a) designações utilizadas para a chamada sobre o Episódio Aracruz e, de modo sucinto, (b) elementos verbais utilizados em outras chamadas, que, por constituírem o mesmo projeto gráfico, mantêm uma interlocução e, assim, produzem efeitos diversos.

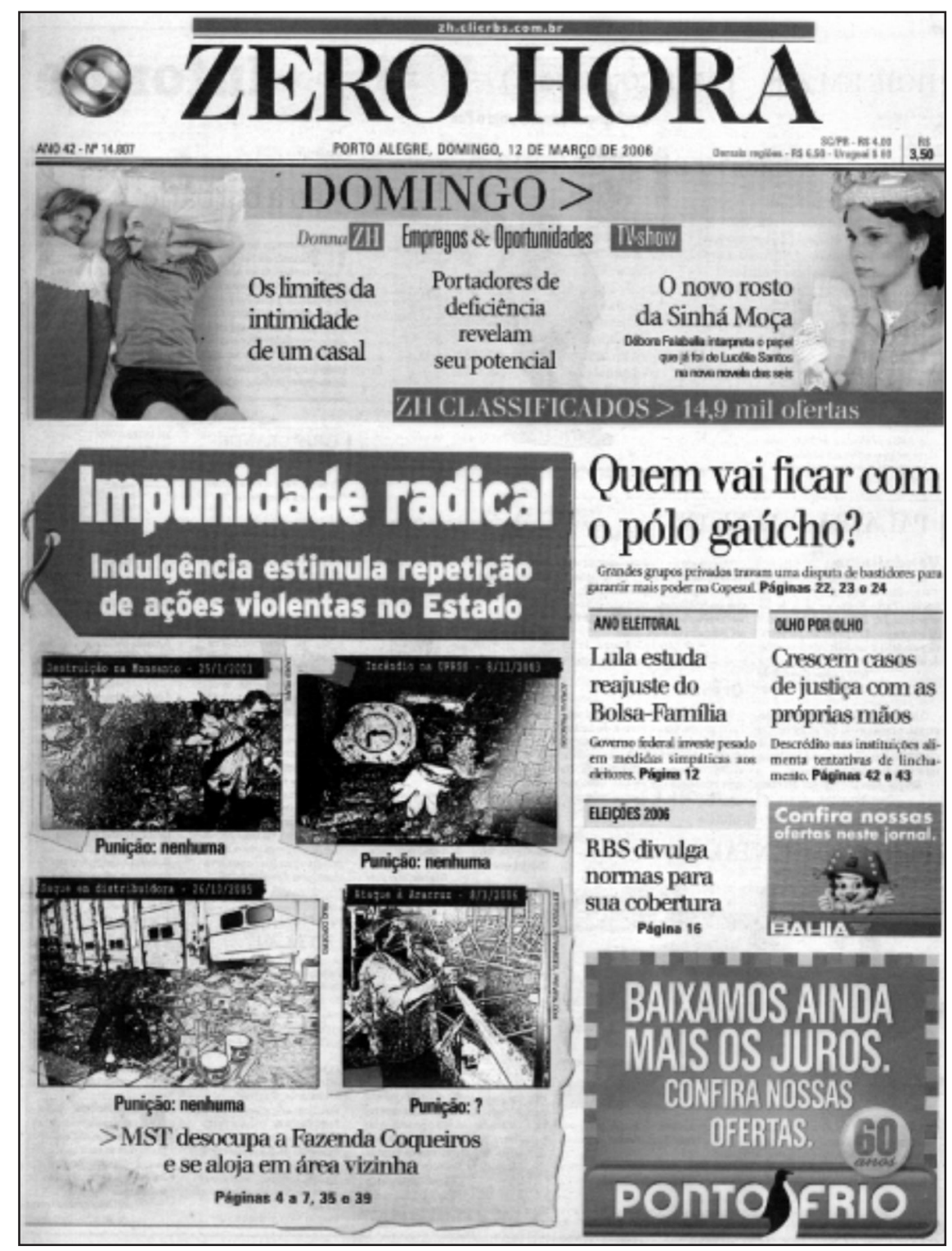

Figura 1: Capa do jornal Zero Hora da edição de 12 de março de 2006 


\section{A capa do jornal e os recursos visuais}

Na capa da edição de 12 de março de Zero Hora, foco desta análise, a chamada sobre o Episódio Aracruz ocupa três colunas de largura (das cinco que subdividem a mancha de um jornal tablóide) por 20 centímetros de altura, preenchendo quase $40 \%$ do espaço total. Na parte inferior, à direita, há dois anúncios de lojas de varejo, os quais, apesar de comporem a capa de jornal, não serão considerados nesta análise. Além da chamada que remete à notícia sobre o Episódio Aracruz, há a manchete do jornal e outras três chamadas. Na parte superior da página, logo abaixo do nome do periódico e ocupando cinco colunas de largura, estão as chamadas dos cadernos dominicais e suas respectivas ilustrações.

Quanto aos aspectos visuais da página, há de se destacar ainda o uso da cor vermelha em diferentes elementos gráficos. Em contextos que tratam de questões sociais, o vermelho nos remete à cor da bandeira do mais importante movimento social de esquerda do Brasil, o MST, com participação ativa na articulação do protesto contra a Aracruz. A cor vermelha aparece nas chamadas dos cadernos dominicais ZH Classificados e Donna $\mathrm{ZH}$. A foto que ilustra o destaque de Donna $\mathrm{ZH}$ (a reportagem "Os limites da intimidade de um casal") também tem um recurso em vermelho: o cobertor que cobre a mulher que está deitada sobre uma cama. O elemento gráfico (uma tarja) localizado acima do nome do jornal, no qual há a inscrição do endereço do site da empresa, neste dia, também é de cor vermelha. Essa tarja é parte integrante do projeto gráfico do jornal Zero Hora, mas varia de cor conforme a diagramação da capa e as cores empregadas. Mesmo não sendo foco desta análise e termos conhecimento de que tal material tenha sido produzido por uma equipe de profissionais de outra área e de fora da redação, é válido ressaltar que o vermelho está presente ainda no principal anúncio da página (lojas Ponto Frio).

Assim, independentemente dos motivos que levaram a tal escolha, a eleição da cor vermelha deixa emergir um efeito de busca de unidade entre diferentes elementos visuais que compõem o todo da página, além de se prestar à utilização de uma etiqueta para a chamada que remete ao Episódio Aracruz. A referida etiqueta vermelha é usada como fundo para o enunciado "Impunidade radical" e a linha de apoio "Indulgência estimula repetição de ações violentas no Estado", que serve de título para a chamada que versa sobre as ações "violentas" protagonizadas pelos movimentos sociais no Rio Grande do Sul nos últimos cinco anos. Esse elemento gráfico se destaca dentre os outros usados na página devido à cor (o matiz vermelho é mais escuro que o usado no anúncio do Ponto Frio) e em função do espaço que ocupa (três colunas de largura e 5,5 centímetros de altura). 
A utilização de uma etiqueta como elemento gráfico não é por acaso. As quatro fotos (em preto e branco) que ilustram a chamada estão dispostas dentro de um quadro de cor amarelo claro (tom pastel), que oferece um efeito de papel envelhecido, tal como documentos de arquivo. Assim é passada a ideia de que os fatos ali apresentados (todos atos de protesto orquestrados e protagonizados pelos movimentos sociais) fazem parte de um acervo catalogado, arquivo-morto. Etiquetas como a apresentada nessa capa também são usadas por magazines para indicar o preço de produtos, principalmente roupas, em liquidação. Pode-se entender, assim, que para o jornal Zero Hora haveria uma grande "oferta", uma banalização, de ações violentas no Rio Grande do Sul, as quais, apesar de serem recorrentes, são apenas registradas em documentos já arquivados.

Importante dizer que o uso de tais recursos visuais para criar uma página esteticamente harmônica e que prenda a atenção do leitor não se configura como uma quebra das normas éticas que regulam a atividade jornalística. Ao contrário, além de atender às prerrogativas da construção discursiva da capa e lhe conferir uma certa estabilidade, a orquestração dos recursos gráficos para a produção da primeira página de um periódico jornalístico condiz com o que nos ensina Schwartz (2003) sobre o debate entre normas antecedentes e renormalizações (ressignificações), fundamental para a construção dos saberes humanos. $\mathrm{O}$ que deve ser ressaltado na capa em foco, no entanto, são as posições ideológicas, avaliativas, que se projetam no conjunto dos recursos verbo-visuais e que devem ser observadas e discutidas, já que o jornal/jornalista, não sendo neutro e estando inserido na história que se faz no dia-a-dia, faz avaliações sobre diferentes segmentos, como é o caso do tom negativo observado em relação às ações atribuídas aos movimentos sociais.

\section{A capa do jornal e os recursos verbais}

Articulados aos expressivos recursos gráficos, os recursos verbais utilizados na capa da edição de 12 de março de 2006 constituem fonte fundamental para observar posições ideológicas empreendidas pelo jornalista/jornal ao produzir a capa de jornal. Para tanto, são observados aspectos relativos (a) às designações utilizadas para a chamada sobre o Episódio Aracruz e, ainda que brevemente, (b) a elementos verbais em outras chamadas que entram em diálogo com a chamada principal.

\section{a) Designações utilizadas na chamada principal: efeitos de sentido em circulação}

Quanto às designações utilizadas para a chamada sobre o Episódio Aracruz, consideramos, dentre as que chamam atenção, a emergência de impunidade, indulgência, punição, radical e violentas. 
Impunidade e radical compõem o título da chamada ("Impunidade radical"), dentro da etiqueta vermelha, enquanto, indulgência e violentas integram o enunciado que, em jornalismo, comumente se designa como linha de apoio: "Indulgência estimula repetição de ações violentas no Estado". Punição compõe a legenda das quatro fotos em preto e branco.

Pela observação desses recursos verbais, indissociados dos visuais, é possível perceber na constituição dos enunciados a circulação de acentos valorativos que orientam para avaliações negativas sobre o Episódio Aracruz. É o caso do título da chamada ("Impunidade radical") que, em letras grandes, maiores do que as de outras chamadas da capa, faz uma espécie de acusação ao considerar a falta de punição das ações atribuídas aos movimentos sociais. Acrescida à impunidade, a palavra radical, além de reforçar o tom acusatório, passa a idéia de que nada se faz para punir os culpados, como se fosse uma questão fechada. Em outras palavras, os responsáveis por avaliar tais ações teriam a postura de não aplicar as penas cabíveis, independentemente do fato. Na circulação de vozes que emergem da chamada do Episódio Aracruz, é válido observar que a designação radical suscita o conflito entre duas perspectivas diferentes: uma, a observada no título em análise, que desqualifica a posição dos representantes do campo jurídico, outra, comumente observada nos veículos de comunicação, que caracteriza como inflexível o posicionamento de movimentos sociais, como a Via Campesina. Tal ressingularização remete às afirmações de Bakhtin de que não existe neutralidade, sendo o enunciado constituído dialógica e ideologicamente em situações de enunciação ímpares. Remete ainda às noções de Schwartz sobre o "fazer" do trabalhador, que no decorrer de sua atividade oferece contribuições únicas (pois é resultado de suas vivências, sua história) para o trabalho, subvertendo as normas descritas nos manuais, de tal forma a deixar sua marca no que é produzido.

O enunciado da linha de apoio, "Indulgência estimula repetição de ações violentas no Estado", que também é destacado graficamente na página, apresenta uma orientação valorativa que não só reforça a ideia de que não há punição, mas também atribui à falta de aplicação de penas o crescimento de ações violentas de movimentos sociais no Estado. Essa posição axiológica é reiterada por diferentes elementos verbais, como é o caso da palavra violentas, que, qualificando as ações, deixa emergir o conflito entre a posição do jornal e a dos movimentos sociais.

No conjunto das designações que integram a chamada principal da capa, a palavra punição suscita uma discussão particular devido ao fato de sobre ela recair grande parte das posições ideológicas antagônicas que circulam nos enunciados. Se considerarmos, conforme o ponto de vista jurídico, que a punição é a aplicação de uma pena civil ou criminal a alguém, 
que somente pode ocorrer após transcorridas etapas na Polícia Judiciária, no Ministério Público e no Poder Judiciário, perceberemos um claro confronto do jornal não só com os movimentos sociais, mas também com a legislação brasileira. Para apurar os responsáveis por fatos como os descritos por Zero Hora, de acordo com a legislação brasileira, é necessário que seja instaurado inquérito policial, durante o qual serão reunidas provas e identificados os autores dos atos infratores. Somente depois disso o Ministério Público, único órgão em nossa sociedade com poder persecutório, pode denunciar alguém à Justiça. Cabe aos juízes a decisão de acolher ou não tal denúncia para a abertura de um processo judicial, durante o qual será dada a oportunidade de defesa do réu. Ao final, é dada a sentença, que pode condenar ou absolver.

Os enunciados que compõem a chamada para o Episódio Aracruz apresentam diferentes acentos de valor, como já observados a partir das designações elencadas, que orientam para a cobrança da punição dos culpados. Essa expressividade é bastante contundente no conjunto de fotografias que, criando efeito de verdade, apela para cenas de destruição, jogando com cores e recursos gráficos. Além disso, a disposição das fotografias, em ordem cronológica, variando de 2001, 2003, 2005 e 2006, dá uma idéia de que está diminuindo o espaço de tempo entre uma ação e outra, o que equivale a um aumento da incidência. Esse direcionamento avaliativo é mais aparente ao observarmos o funcionamento discursivo da designação punição nas fotografias. As três primeiras fotos apresentadas possuem uma mesma legenda - "Punição: nenhuma" - que, se do ponto vista formal, é uma repetição, do ponto de vista enunciativo, configura-se como um novo enunciado a cada ocorrência, com sentido dinâmico que, não deixando de entrar em confronto com os movimentos sociais e com a legislação brasileira, acusa a falta de Justiça em três diferentes ações dos movimentos sociais. $\mathrm{O}$ tom acusatório é reiterado pelo uso do pronome "nenhuma" (em referência à "punição") que apresenta índices valorativos que indica a falta de qualquer medida contra os responsáveis pelos atos. $\mathrm{Na}$ quarta fotografia, a do Episódio Aracruz, a legenda sofre um deslocamento bastante sugestivo. No lugar de "nenhuma", após "punição", aparece um ponto de interrogação: "Punição: ?". Esse sinal gráfico, entrando em dissonância com as outras ocorrências das ações que não tiveram punição, remete à incerteza, questionamentos e insegurança. Como em três dos quatro episódios relacionados na capa do Jornal, até a data da edição (12/03/2006), os inquéritos policiais não haviam sido concluídos, é possível perceber o confronto entre as posições assumidas pelo jornal e a legislação brasileira. O quarto e último fato (o Episódio Aracruz) havia ocorrido há quatro dias, tempo insuficiente para a conclusão das etapas processuais no Poder Judiciário. 
Sem nos estendermos na reflexão, mas sem deixarmos de reconhecer a pertinência de ampliar a análise abrangendo outras designações, como os verbos desocupa e se aloja em referência ao MST no linha inferior da chamada principal, é válido fazer algumas considerações antes de passarmos para a outra etapa da análise. Tendo em vista a constituição verbo-visual dos enunciados da chamada principal, é possível perceber uma construção voltada para causar impacto, o que não acontece com as matérias publicadas dentro do corpo do jornal que apresentam um detalhamento. Percebemos, na capa, o confronto com alguns dos preceitos básicos do jornalismo, descritos na maioria dos manuais de redação: evitar tomar para si (jornalista/jornal) a responsabilidade de avaliar fatos do cotidiano, sem que para isso tenha consultado fontes, isto é, especialistas no tema. Essa medida se faz necessária em função de a esfera jornalística se configurar como um campo de passagem, ou seja, trata de fatos de esferas diversas e se utiliza, para tanto, do conhecimento de especialistas de outras áreas que não a jornalística para subsidiar sua produção. Essa prática deve ser objeto de reflexão, uma vez que, sem um olhar crítico, um leitor desavisado possivelmente vai aceitar como "verdade" as versões apresentadas e os efeitos criados pelos enunciados da capa do jornal.

\section{b) Elementos verbais em outras chamadas: relações dialógicas desencadeadas}

A seguir discutimos brevemente duas chamadas secundárias, que, na mesma página, mantêm um diálogo com a chamada sobre o Episódio Aracruz, criando, assim, efeitos de sentido outros.

"Quem vai ficar com o pólo gaúcho?"

Mesmo em corpo menor que a chamada do Episódio Aracruz, o enunciado em forma de pergunta "Quem vai ficar com o pólo gaúcho?" é manchete da edição de 12 de março de 2006 do jornal Zero Hora. Vale destacar que não é usual a utilização de perguntas, mesmo em títulos, sendo desaconselhado o seu uso pelos manuais de redação por remeter a dúvidas, efeito contrário ao almejado no gênero notícia, que tem como ponto referencial a busca por efeitos de objetividade, veracidade e imparcialidade.

O enunciado, construído como um questionamento, põe em xeque a situação de um importante segmento da economia do Rio Grande do Sul: o polo petroquímico. Tal acepção remete a um efeito de incerteza em relação ao futuro do estado do Rio Grande do Sul, o qual é impossível desatrelar do efeito sugerido pela chamada do Episódio Aracruz, que faz referência à impunidade existente no estado gaúcho com relação a "ações violentas".

"Olho por olho" 
A expressão "Olho por olho, dente por dente" está registrada num dos 282 artigos do Código de Hamurabi (1792-1750 a.C.), o qual instituiu a vingança como preceito jurídico no Império Babilônico. É base também para a Lei de Talião, que prescreve ao transgressor a pena igual ao crime que praticou. A Lei de Talião (do latim Lex Talionis: lex: lei e talis: tal, parelho) consiste na rigorosa reciprocidade do crime e da pena, por isso é frequentemente expressa pela máxima olho por olho, dente por dente. É uma das mais antigas leis existentes.

O jornalista/jornal lançou mão de parte da expressão "Olho por olho" - para identificar uma das chamadas da capa, usando-a como cartola para o título "Crescem casos de justiça com as próprias mãos". Aqui, novamente, é perceptível o efeito de sentido de que o poder público no Estado não é atuante. $\mathrm{O}$ enunciado "Descrédito nas instituições alimenta tentativas de linchamento", logo abaixo da chamada, segue a mesma orientação avaliativa e indica que os próprios cidadãos estão tomando para si a obrigação de punir os supostos culpados de crimes. $\mathrm{O}$ enunciado configura-se como mais uma alusão à impunidade existente no Rio Grande do Sul, explicitada na chamada sobre o Episódio Aracruz.

\section{Considerações finais}

Com o propósito de analisar discursivamente a capa de domingo do jornal Zero Hora do dia 12 de março de 2006 na cobertura do Episódio Aracruz, evento de grande repercussão na mídia gaúcha, procedemos à observação dos enunciados em sua materialidade verbal e visual, procurando verificar relações dialógicas estabelecidas de modo a recuperar efeitos de sentido em circulação. Nessa perspectiva, procuramos observar a chamada relativa ao Episódio e alguns aspectos das chamadas secundárias, que não deixam de ter relevância ao estabelecer diálogo com a principal.

Os enunciados eleitos para a construção da chamada sobre o Episódio Aracruz são, sem dúvida, impactantes. Os recursos gráficos utilizados para compor tal chamada - como a cor vermelha, a tarja em forma de etiqueta e as fotografias em preto e branco, criando o efeito de envelhecimento - indissociáveis dos recursos verbais - como as designações "impunidade", "radical", "indulgência", "violentas" e "punição" - não escondem a posição avaliativa do jornal em relação aos movimentos sociais. Tal postura reativa é reiterada pela ordem cronológica da apresentação das fotografias em que se, por um lado, reforça a ideia da "repetição de ações violentas no Estado", por outro, elenca a falta de aplicação de penas pela Justiça. Nessa textura verbovisual, é possível perceber um confronto ideológico entre a voz de Zero Hora (que cobra medidas punitivas) e a da Justiça (que 
cumpre prazos e tramitação de processos), pois, até a data da publicação do jornal, nenhum dos quatro episódios havia sido julgado; portanto, não poderia ter havido punição.

É válido destacar ainda que, pela análise de chamadas secundárias que compõem a capa, várias relações dialógicas são observadas em relação à chamada do Episódio Aracruz, permitindo observar, pela expressividade dos enunciados, efeitos de sentido voltados para o estado de insegurança que se encontra o Rio Grande do Sul. Tais pistas fazem ressoar acentos apreciativos que, ao se distanciarem das prescrições dos manuais de redação, parecem se aproximar da linha editorial da empresa de comunicação, que tem demonstrado, através de editoriais, discordar das ações de movimentos sociais como o MST e a Via Campensina.

Os enunciados analisados, apesar de constituirem discursivamente a capa, não seguem em parte as prescrições dos manuais de redação, que recomendam a busca de "isenção" e "neutralidade" e desaconselham o uso de designações que possam fornecer avaliações feitas pelo profissional. Essas interferências do jornalista/jornal, no entanto, não comprometem a esfera jornalística em que está inserida a notícia e a capa de jornal, que, se por um lado, está de acordo com a relativa estabilidade dos enunciados (BAKHTIN, 1952-1953/2003), diferentes possibilidades de concretizar o gênero, desde que algumas recorrências possam ser percebidas, por outro, ratifica o estatuto lacunar das normas e do trabalho (imprevistos), preconizado por Schwartz (2003), em que há sempre espaço para (re)elaborações do trabalhador.

No debate entre as normas antecedentes e as renormalizações, o jornal, sem dúvida, não deixa de mostrar suas avaliações na tessitura dos enunciados que compõem a primeira página. A voz de Zero Hora, constituída por um emaranhado nada harmônico de outras vozes, de cunho político, social, jurídico, etc., na cobertura do Episódio Aracruz, deixa ressoar alianças, rompimentos, dentre outras relações dialógicas, com diferentes segmentos da sociedade, o que, sem dúvida, exige uma visão crítica de um leitor nem sempre preparado para tal ato.

\footnotetext{
Abstract:

This paper aims to make a discursive analysis of March 12, 2006 first page of Zero Hora (RS), focusing on the ways dialogical relationships are established in order to identify characteristics and sense effects regarding the coverage of an event of great repercussion in "gaucho" media that we call for research shake "Episódio Aracruz". The analysis is based on theoretical grounds
} 
developed by the Bakhtin Circle and establishes an interlocution with an ergological viewpoint. For methodological reasons, the analysis is organized in two interdependent groups. The first one resents a reflection concerning the cover of the periodical studied and the effects produced by visual resources there used (such as color, space and graphic elements). The second one analyzes verbal resources selected for the construction of the cover, considering (a) names used for the lead regarding Episódio Aracruz; and, succinctly, (b) verbal elements used in other leads, that, because of being constituents of the same graphic project, keep an interlocution and, thus, produce different effects. The results of the reflection indicate that the analyzed utterances, by not following the guidelines of newspaper style manuals, are highly evaluative in the intrinsic relationship between the verbal and visual domains, disclosing the relative stability of genres and ratifying the lacunar statute of work norms. In this discursive process, the position of the newspaper emerges in a confusion of voices in the covering of Episódio Aracruz, allowing a resonance amongst other dialogical relationships, the rupture with social movements, what demands a critical reading for understand senses circulating therein.

Keywords: Dialogical relationships. Printed newspaper first page. Episódio Aracruz.

\section{Referências}

BAKHTIN, M. Problemas da poética de Dostoiévski (1929). 2. ed. Trad. Paulo Bezerra. Rio de Janeiro: Forense Universitária, 1997. O discurso no romance (1934-1935). In: Questões de literatura e de estética: a teoria do romance. Trad. Bernadini et al. 4. ed. São Paulo: Unesp, 1998. p.71-210.

Os gêneros do discurso (1952-1953). In: . Estética da Criação Verbal. 4. ed. Trad. Paulo Bezerra. São Paulo: Martins Fontes, 2003. p.261-306.

O problema do texto na Lingüística, na Filologia e em outras Ciências Humanas (1959-1961). In: Estética da criação verbal. 4. ed. Trad. Paulo Bezerra. São Paulo: Martins Fontes, 2003. p.307-335.

BAKHTIN, M./VOLOCHINOV, V. Marxismo e Filosofia da Linguagem (1929). 11.ed. São Paulo: Hucitec, 2004. 
BRAIT, B. e ROJO, R. Gêneros: artimanhas do texto e do discurso. São Paulo: Escolas Associadas, 2003.

DI FANTI, M. G. Palavra. In: Flores, V., Barbisan, L., Finatto, M., Teixeira, M. (org.), Dicionário de Linguística da Enunciação. São Paulo: Contexto, 2009. p.182.

GRILLO, S. A produção do real em gêneros do jornal impresso. São Paulo: Humanitas, 2004.

GUIA de Ética e Responsabilidade Social da RBS/Rede Brasil Sul. Porto Alegre: RBS Publicações, 2004.

LAGE, N. Estrutura da Notícia. 4. ed. São Paulo: Editora Ática, 1998. LIMA, E.; DI FANTI, M.G.C. Da constituição dialógica da capa de jornal: efeitos de sentido em perspectiva. In: Anais do XIII Colóquio Internacional de Comunicação para o Desenvolvimento Regional. Pelotas, 2008.

SANT'ANNA, V. O trabalho em notícias sobre o Mercosul: heterogeneidade enunciativa e noção de objetividade. São Paulo: Educ, 2004.

SCHWARTZ, Y. Travail et philosophie: convocations mutuelles. 2. ed., Toulouse: Octares, 1994. . Trabalho e saber. Trabalho $\mathcal{E}$ Educação, Revista do Nete, UFMG, vol.12, n.1, jan/jun 2003. p.21-24.

. DURRIVE, Y. (org.). Trabalho \& ergologia: conversas sobre a atividade humana. Trad. Milton Athayde e Jussara Brito et al. Niterói: EDUFF, 2007.

SILVA, C.E.L. (coord.). Manual de Redação da Folha de São Paulo. 9. ed. São Paulo: PubliFolha, 2005. 